
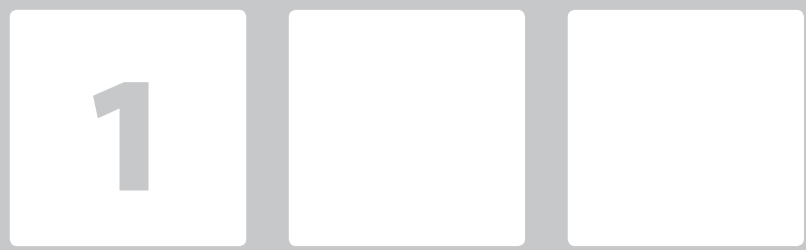

\title{
PRÁTICAS DE GOVERNANÇA PÚBLICA MUNICIPAL: ANÁLISE INFORMACIONAL DOS SÍTIOS ELETRÔNICOS EM PORTAIS DE TRANSPARENNCIA
}

\section{Municipal Public Governance Practices: Informal analysis of electronic sites in transparency portains}

\section{Silvio Parodi Oliveira Camilo}

Pós-doutorado em Ciências Contábeis (PPGC-UFSC). Prof. de Pósgraduação do Mestrado em Desenv. Socioeconômico (PPGDS). Universidade do Extremo Sul Catarinense (UNESC). Criciúma, SC. Brasil.e-mail:autor1@xxx.com

\section{Rosana Vieira Alves Manenti}

Mestra em Desenv. Socioeconômico pelo Programa de PósGraduação em Desenv. Socioeconômico (PPGDS). Universidade do Extremo Sul Catarinense. Criciúma, SC. Brasil.e-mail:autor2@xxx.com

\section{Cristina Keiko Yamaguchi}

Dra. em Engenharia e Gestão do Conhecimento (EGC) da Universidade Federal de Santa Catarina (UFSC), Docente do Programa de Pós-Graduação em Desenv. e Sociedade na Universidade Alto Vale do Rio do Peixe (UNIARP).Criciúma, SC. Brasil.e-mail:autor3@xxx.com

\section{RESUMO}

O objetivo geral do presente estudo é identificar práticas de governança pública, por meio da estrutura obrigatória e recomendável nos portais de transparência, na geração de informação à sociedade nos municípios da microrregião de Criciúma-SC, e sugerir proposições de pesquisa. A abordagem é qualitativa, com objetivos descritivos, com emprego do exame de dados informacionais mediante a disposição por e-governo. Os dados levantados sugerem que os gestores dos municípios da amostra não cumprem na íntegra as estipulações obrigatórias estabelecidas na legislação pertinente. Não se pode afirmar que o gestor público transparece sua gestão, por meio do e-governo, à população e aos interessados de modo compreensível e eficiente. Vê-se que os municípios dessa região não adotam boas práticas de governança pública, afrontando exigências normativas. Por tais práticas - ou descumprimentos, pode-se inferir que a desídia afronta aos direitos à cidadania e desafiam à sociedade.

Palavras-chave: Gestão Pública. Governança Municipal. Transparência Pública.

\section{ABSTRACT}

The general objective of this study is to identify public governance practices, through the obligatory and recommended structure in transparency portals, in the generation of information to society in the municipalities of the Criciúma-SC microregion, and to suggest research proposals. The approach is qualitative, with descriptive objectives, using informational data analysis through the provision by e-government. The data collected suggest that the managers of the municipalities of the sample do not fully comply with the mandatory stipulations established in the relevant legislation. It can not be said that the public manager transforms his management, through e-government, to the population and the interested parties in an understandable and efficient way. It is seen that the municipalities of this region do not adopt good practices of public governance, facing normative requirements. By such practices - or noncompliance, it can be inferred that the deity faces the rights to citizenship and defy society.

Keywords: Public Management. Municipal Governance. Public Transparency. 


\section{INTRODUÇÃO}

Diretivas relacionadas a gestão pública, suas responsabilidades, transparência e legalidade foram estabelecidas a partir de instituições internacionais como a Organização das Nações Unidas (ONU) e pela Organization for European Cooperation and Development (OECD) (KISSLER; HEIDEMANN, 2006). No Brasil. a partir da Constituição da Republica de 1988, a reestruturação político-institucional promoveu importante mudança na administração pública, tanto sob o prisma orgânico quanto funcional (JUSTINO DE OLIVEIRA, 1997). A Constituição Brasileira em seu art $31, \S 3^{\circ}$., estabeleceu acesso irrestrito das contas municipais ao qualquer cidadão interessado, e por meio do art. 37, que trata da administração pública, fixou os princípios da publicidade e da moralidade (FIGUEIREDO, 2007).

Com essas diretrizes, a interação e a proximidade entre e governo e o cidadão, a responsabilização por parte do ente governamental se tornou mais ampla, exigindo processos informacionais com transparência e uteis (VELASCO, 2014). Audiências Públicas, Observatórios, Organizações não governamentais, com interesse no ente público, foram mecanismos e organizações institucionais constituídas para proteger a coisa pública e promover maior transparência e controle da gestão. Essa nova consideração tem permitido a aproximação do cidadão às ações dos governantes, inibindo, de certo modo, atos discricionários.

A sociedade da informação está presente é uma realidade, pois mudanças são rápidas e constantes isto devido principalmente aos avanços da tecnologia da informação e comunicação-, com uso intenso da internet e mutações heterogêneas do estado social do cidadão. Neste complexo contexto, cabe ao agente político compreender esses movimentos, produzir respostas e soluções aos desafios encontrados no âmbito da gestão pública. Neste sentido, um dos desafios mais acirrados do gestor público, para além do cumprimento da legislação, está em estabelecer e fortalecer uma confiança mútua na relação entre governo e sociedade. Um dos caminhos possíveis para o gestor público é a adoção de boas práticas de governança, compreendendo transparência, participação e limitações por intermédio de responsabilização de atos reprováveis.
Embora este debate tem se mostrado mais presente na literatura brasileira, boas práticas na gestão pública se intensificaram a partir dos estudos e de Hood e Jackson (1991). Esses autores nominaram de nova gestão pública (New Public Management), caracterizada pela separação entre gestão (como fazer) e questões políticas (o que fazer), justamente por que decisões nesse âmbito são pautadas por dilemas, muito diferenciadas da gestão privada. Dessa segregação se originaram a administração pública - com raízes na ciência política e na política pública; a nova gestão pública - com caráter racional e gerencial em termos de decisão; e a nova governança pública - com base na sociologia organizacional e na teoria das redes (OSBORNE, 2007).

Essa discussão foi relevante para o avanço do debate atinente a governança pública. A partir disso, Osborne (2010) aponta a existência da segregação entre política pública e a prestação de serviços públicos. A governança pública é aplicada como um processo no qual as organizações e a sociedade tomam determinadas decisões, que determinam quem será o agente e como este deverá fazer a prestação de contas. Contudo, a participação do cidadão torna-se cada vez mais intensa nos campos que afetam a sociedade, emergindo discussões sobre a participação do cidadão na tomada de decisão e também na discussão sobre o conceito de governança (CONDE, 2015).

Por intermédio de alguns princípios, estabelecidos pelo legislador, o gestor público se obriga a realizar práticas de governança de sua gestão pública, permitindo à sociedade conhecer, fiscalizar e organizar pleitos perante o agente político que está no poder. Tais limitações o conduzem a gerir a coisa pública de acordo com as necessidades encontradas pela sociedade. Neste sentido, Conde (2015) caracteriza a governança pública engajada em princípios como: transparência, prestação responsável das contas e relações éticas.

Vê-se que o acesso à informação passou a ser um direito inarredável do cidadão, dado que se tornou instrumento da democracia, a implementação das obrigações estabelecidas pelo conjunto de normas ao gestor público trouxe ônus à gestão, isso por que exigiu investimentos em recursos administrativos, estruturais, tecnológicos e informacionais. Nesse sentido, Michener, Moncau e Velasco (2014) entendem 
que tal ônus cria barreiras desestimulando os agentes as adequações legais neste aspecto.

As leis possuem caráter obrigatório ao gestor e informativo para o cidadão, tornando-se uma base para fiscalização da sociedade e possibilitando a intervenção social, no sentido de promover melhorias no uso dos recursos públicos. Em termos de impacto histórico e social, vê-se que são relativamente recentes. Este trabalho se insere na corrente que investiga a governança pública e seus mecanismos, integrando campo informacional. Há recomendações no sentido de se ampliar pesquisas qualitativas referentes às contas públicas e o interesse dos usuários (PLATT NETO et al., 2007), e se justifica por sugestões como as de Castro Alcântara, Pereira e Ferreira Silva (2015, p.15), no sentido de se "investigar práticas de gestão social e governança pública no Brasil e em que medida elas são empiricamente distintas e empiricamente complementares". Este estudo pretende contribuir com outros estudos que se ocupam da governança pública no âmbito municipal, contribuindo com a integração de pressupostos da ciência da informação, accountability e conhecimento gerado por meio eletrônico para a participação da sociedade (ROCHA, 2013).

O objetivo geral do presente estudo é identificar práticas de governança pública, por meio da estrutura obrigatória e recomendável nos portais de transparência, na geração de informação à sociedade nos municípios da microrregião de Criciúma-SC, e sugerir proposições de pesquisa. Em pesquisas realizadas, não se encontrou estudos que analisassem aspectos da transparência e da informação fixados pelo legislador e buscassem identificar o cumprimento de exigências legais. Ou seja, em que grau os portais da transparência municipais atingem os objetivos estatuídos pelas normas informacionais? São (in)efetivos e/ou falhos em seus canais de estreitamento com o cidadão?

Pelos princípios elencados acima, espera-se que este trabalho se incorpore à corrente que se ocupa das relações entre o ente público e a sociedade. Revela-se importante investigar esse tema mais profundamente, pois quanto mais difundidas são as práticas de atos do governo, mais eficaz será a gestão pública. Isso pode instigar o cidadão a estar presente, exercendo seu papel de agente participativo. Esse estudo também é uma maneira de divulgar informações dos portais de transparência dos gestores municipais, para que a sociedade conheça as imposições legais às quais os gestores públicos estão submetidos e os canais informacionais de acesso para fiscalizar decisões da gestão pública.

\section{FUNDAMENTAÇÃO TEÓRICA}

Nesta seção, o estudo apresenta os fundamentos da gestão e da governança pública, compreendendo seus mecanismos contributivos a participação da sociedade na gestão pública.

\subsection{Gestão pública}

Reichard (1998) destaca a partir da década de 1990 se nota mudança de orientação nos conceitos de gestão pública. Foi dirigida especial atenção exigindo reformas no setor público. O sentido de responsabilização por efetividade nos projetos, assim como por desempenho dos mesmos, mostrou-se crescente. Conclui, com esse interesse social foram desenvolvidos indicadores-chave base para ampliar a transparência aos interessados.

Ao buscar entendimento sobre administração pública e gestão pública, Santos (2006) conceitua administração pública como a gestão dos interesses e bens da comunidade, na esfera federal, estadual e municipal, seguindo as leis, a moral, na busca para o bem comum, a gestão pública possui as mesmas características da administração pública, apenas com uma especificidade, ocorre por um período de tempo determinado ou por meio de mandato.

A gestão púbica pressupõe natureza de conservação, encargos de defesa e interesse, aprimoramento e serviços em função da coletividade. Existem na constituição federal alguns princípios para que se torne realidade, e o gestor público que desvia este foco trai o mandato ao qual foi instituído, porque a sociedade o instituiu para um único objetivo: atingir o bem-estar social. Conforme o art. 37 da Constituição da República Federativa do Brasil, de 05 de outubro de 1988, existem princípios norteadores da gestão pública, que são: legalidade; impessoalidade; moralidade; publicidade; finalidade; indisponibilidade e igualdade. 
No Brasil, as finanças públicas, por meio dos princípios, limites instituídos, condições e uso das normas administrativas de base legal em vigência, determinam um desafio para os governantes nas diversas esferas, impondo uma modificação em processos, comportamentos, no conhecimento técnico e na forma de gestão. Em função da Constituição de 1988, da heterogeneidade das classes sociais, econômicas, culturais, políticas e institucionais nos municípios, tal situação encaminha os governantes a repensar a gestão para tentar atender a demanda do município (MELO; MONTEIRO; FADUL, 2007).

\subsection{Governança pública}

Osborne (2007, p. 383), apresentou como contraste à nova governança pública elementos chave da administração pública e da nova gestão pública. Quanto a raízes teóricas, entendeu a administração pública (AP) embasada na ciência política e nas políticas públicas; a nova gestão pública (NPM) focada na racionalidade e na teoria de escolhas públicas; a nova governança pública (NGP) na sociologia organizacional e na teoria das redes. Quanto a natureza do estado, foco e ênfase, a AP é unitária, focada no sistema político e com ênfase na implementação política; a NPM é desagregada, gestão intra-organizacional e com atenção nas entradas e saídas nos serviços; e a NGP é plural e pluralista, com foco na governança inter-organizacional e ênfase nos resultados e processos dos serviços.

Em adição, Osborne (2007) comparou elementos do relacionamento externo, mecanismos de governança e valor-base. $\mathrm{Na} \mathrm{AP}$ o aspecto relacional é centrado no ambiente político, com governança hierárquica e ética baseada em princípios concernentes ao setor público. A NPM possui relacionamento externo com base em contratos independentes dentro do ambiente competitivo, governança de mercado nos moldes clássicos e neo-clássicos e pautado na eficiência e na competição de mercado. Já a NGP tem fornecedores preferenciais e após interdependentes e em curso, com governança na confiança por meio de contratos relacionais e valores neo-corporativista.

Nesta discussão, Rodrigues (2010) refere que a diferença entre a governança no setor privado ou público não se encontra no conceito, mas sim na forma de utilizar o conceito e seus princípios na prática. No setor privado se busca a competividade para a geração do resultado e no setor público a conformidade diante dos seus diversos stakeholders.

Rocha (2013) sugere que investigar práticas e atuações de instituições polícias, por instrumentos de accountability, é um meio de melhorar o desempenho do Estado e desenvolver a democracia no país.

Pode-se dizer que há uma nova fase moderna das organizações públicas, pautadas por novos princípios e métodos de governança (PATAPAS; RAIPA; SMALSKYS, 2014). Essa nova ordem sugere evolução na democratização da coisa pública. A transparência da gestão pública com dispersão informacional do planejamento e das ações favorece o estreitamento com a sociedade e possibilitam discussões aproximando interesses - da gestão pública e dos cidadãos. Porém, embora o arcabouço legal seja um instrumento que impulsione comportamentos do gestor público, a efetividade da governança pública será alcançada com a participação dos atores como administração pública, sociedade local, associações, igrejas, sindicatos, organizações não governamentais (KISSLER; HEIDEMANN, 2006).

\subsection{Mecanismos de governança}

No âmbito da governança pública mecanismos foram desenvolvidos, por meio de normas, no sentido de estabelecer relação mais harmoniosa entre o agente público e a sociedade. A gestão pública, mediante um conjunto de atividades informacionais, tem oportunizado o conhecimento de uma variedade de dados abertos ampliando maneiras de inclusão e controle social.

\subsubsection{Responsabilidade fiscal e a transparência pública}

Com a necessidade de termos um equilíbrio e controle nas contas públicas, uma gestão planejada e transparente por parte do governante e com a interação do cidadão, houve a publicação da Lei Complementar no 101 de 04/05/2000, designada como Lei de Responsabilidade Fiscal (LRF), para a responsabilização na gestão fiscal por meio das finanças públicas (MELO et al., 2007). A LRF nasceu com 
a finalidade de manter um equilíbrio entre as receitas e despesas, sendo fiscais e orçamentarias para a não geração de endividamento.

No Brasil existe uma estrutura legal, composta por um sistema orçamentário constituído por três peças: o Plano Plurianual (PPA), a Lei de Diretrizes Orçamentárias (LDO) e a Lei Orçamentária Anual (LOA). Buscando uma valorização deste sistema orçamentário, a LRF impõe normas para que estas peças desempenhem seu papel corretamente.

Um precedente relevante ao impacto positivo da transparência e da prestação de contas da gestão pública é o desempenho. O interesse em dar publicidade aos atos de gestão está diretamente relacionado ao nível de informação disponibilizada (REICHARD, 1998). Ou seja, quanto mais ampla e clara a maneira com que se divulgam os atos e resultados da gestão melhores são os resultados obtidos pelos gestores.

Com relação ao tema transparência com participação na administração pública, existem duas vertentes: a que se refere à disponibilidade de informações e a que está atrelada ao controle social feito pela própria população. No período anterior à reforma de 1995 os governos não preparavam, não elaboravam regularmente os números acerca da administração pública em relação à dinâmica de trabalho e os processos. A partir da reforma, e com apoio da tecnologia de gestão da informação, iniciou-se a averiguação e publicação dos números em relação à administração pública, tornando-se essencial para o controle e a gerência dos recursos (PECI; PIANANTI; RODRIGUES, 2008).

Em relação ao controle social, a transparência vem sendo um elemento essencial na transferência dos processos burocráticos, vindo a sociedade a passar pela desburocratização e flexibilização dentro da administração pública, tornando-se um fiscalizador dos recursos, da concorrência entre fornecedores e impulsionando a tomada de decisão. E assim a sociedade começa a tornar mais legítima a ação do estado, sendo um participante ativo no processo.

Em razão da abrangência relacional e contratual que se estabelece, naturalmente, entre a gestão pública e os fornecedores de produtos e serviços em geral, maior transparência nas contratações mais custosas mitigam problemas de corrupção. Nesse aspecto, leis podem proibir e minimizar as chances de aparecimento da corrupção (OSBORNE, 2010), mas a forma com que a gestão transparece essas relações pode evitar o incentivo à práticas perversas. Daí a maneira como o gestor divulga e presta contas de seus atos pode ser uma proxy para apurar o grau de vulnerabilidade de corrupção.

Platt Neto et al. (2007, p. 85) asseveram que "a divulgação das contas públicas pressupõe o fornecimento de informações confiáveis e relevantes aos interesses dos usuários, apoiando o processo decisório". Mediante a Figura 1 propuseram três dimensões da transparência: a publicidade; a compreensividade das informações; e a utilidade das decisões.

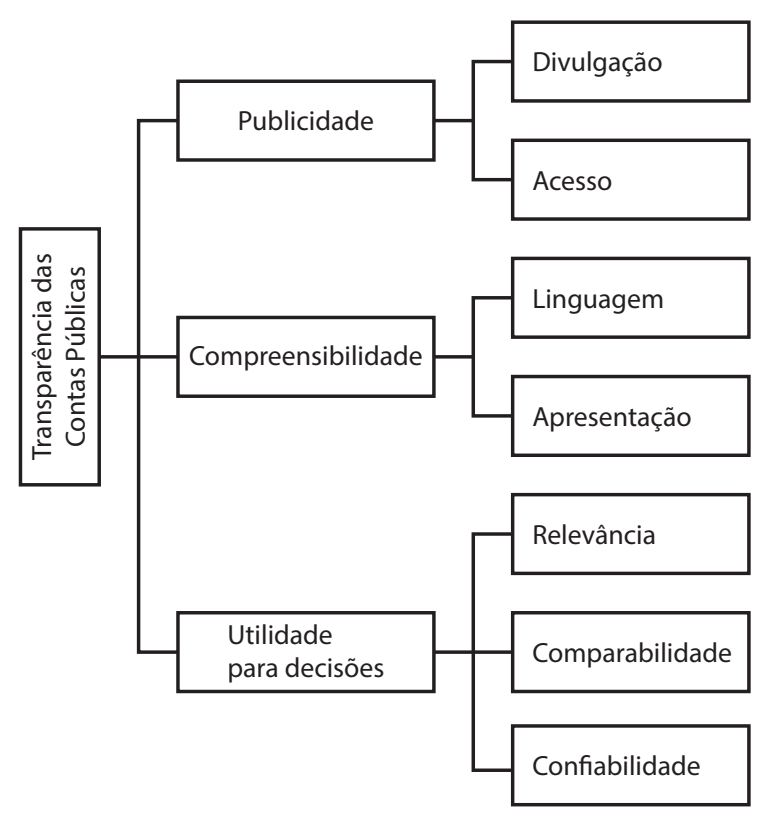

Figura 1 Elementos da transparência das contas públicas Fonte: Platt Neto et al. (2007, p. 85).

A publicidade pressupõe ampla forma de divulgação informacional aos interessados, permitindo acesso por múltiplos meios, com custo reduzido e intuitivo aos usuários. A dimensão compreensividade está relacionada ao entendimento do conteúdo demonstrado. A linguagem deve simples, acessível e orientada para o entendimento dos usuários. Já a utilidade está vinculada a natureza dos dados informacionais. Devem ser confiáveis, úteis e relevantes.

\subsubsection{Portal de transparência}

Em que pese o arcabouço normativo estabelecer um amplo conjunto de dados informacionais, não se pode pressupor que, com isso, haverá transparência 
absoluta e completa. Justamente, nessa linha, Reichard (1998) entende que se deve considerar que as informações prestadas pelo gestor público são imperfeitas, portanto não se pode alcançar a transparência completa.

Aduz consideração (p. 7), no sentido de que a transparência pode estar relacionada a diferentes objetivos, dentre os quais: em matéria de eficiência e eficácia; à qualidade dos serviços; a capacidade de resposta e à orientação aos interessados; a legalidade; a legitimidade e a tomada de decisões democráticas.

O portal tende a ser o primeiro contato do indivíduo com um sítio, e possui duas características principais: compartilhamento de informações e integração de processos e pessoas na prestação de serviços on-line, contribuindo para uma gestão integrada com a comunidade interna e externa, gerando padrões e diminuindo custos nos procedimentos (PAULA; CIANCONI, 2007).

O portal da transparência vem sendo construído para ser um canal aberto, para que qualquer indivíduo da sociedade, sem conhecimento prévio, possa acessar de forma livre, sem o uso de senhas ou qualquer tipo de preenchimento de formulário que identifique o cidadão. Esta iniciativa tem o argumento ambiente institucional como um dos instrumentos ferramentas para o controle social (LOUREIRO; TEIXEIRA; PRADO, 2008). Com o aumento da transparência, o cidadão tem o potencial de ser um agente no controle dos gastos públicos. E para que isto ocorra, esta transparência tem que ser de uma linguagem compreensível e acessível para todos os níveis da sociedade.

Há apontamentos na literatura que entendem que com os portais de transparência, uma vez devidamente esclarecedores em nível de transparência pública, os cidadãos passam a ter informações mais adequadas sobre os gastos da gestão pública, atuando dessa maneira como inibidores de corrupção (RAUSCH; SOARES, 2010).

\subsubsection{Acesso à informação}

Para os autores Aun e Câmara (2005, p. 2), e na intenção de haver uma política digital, existem quatro aspectos fundamentais para a interação do que será divulgado e como a sociedade receberá a divulgação: i) o entendimento das especificidades locais e regionais, bem como do conteúdo informacional que as caracterizam; ii) a necessidade de estratégias distintas as diferentes sociedades; iii) a identificação, o estudo e o compartilhamento do conhecimento comum envolvido; e iv) a identidade e os valores socioculturais da sociedade como um todo.

Segundo os autores, com estes quatro aspectos sendo considerados como uma política de inclusão, a inserção social e global do cidadão aumentará em toda sociedade, contemplando todos os participantes desta cadeia.

Salientasse, não somente fazer a inclusão do cidadão na sociedade da informação e digital, mas sim dar a oportunidade do crescimento intelectual para que o mesmo tenha a ciência da importância da sua participação na construção da sociedade (FREIRE, 2008). Existe o desafio de criar, produzir tecnologias intelectuais para não apenas divulgar a informação, e sim estar a transformar esta informação em conhecimento e futuras ações na sociedade.

\subsubsection{Governo eletrônico (e-gov)}

Com a chegada dos movimentos da reforma do Estado no final dos anos 90, houve o surgimento do governo eletrônico, devido à presente demanda de serviços da área pública oferecidos ao cidadão pela internet (CUNHA; SANTOS, 2005).

Por meio das novas tecnologias de informação, mais especificamente a internet, foi implementado no Brasil o Governo Eletrônico (e-gov), para uma maior interação com os cidadãos, como uma ferramenta de serviços on-line e ao mesmo tempo como informativo, na atuação de uma democracia participativa (PAULA; CIANCONI, 2007). Por sua vez, o e-gov busca organizar e disseminar as informações referentes à gestão do governo por meio do compartilhamento do conhecimento gerado, havendo uma articulação transparente entre o cidadão e seu governante na construção de uma sociedade participativa.

Importante destacar acerca do surgimento do Governo Eletrônico no Brasil, mediante políticas e ações, destacam-se (i) o surgimento do e-Gov no ano 2000, com a constituição de um grupo de trabalho interministerial; (ii) se fundamenta por meio de três eixos: participação cidadã; melhoria do gerenciamento interno do estado; e integração com parceiros e fornecedores; iii) a criação do comitê executivo do 
governo eletrônico (cege) em 2000 com a incumbência de formular políticas, estabelecer diretrizes, coordenar e articular as ações de implantação do governo eletrônico (GOVERNO DIGITAL, 2015).

Segundo o relatório consolidado, o governo eletrônico possui alguns papéis em relação à transformação social: promotor da cidadania e do desenvolvimento; funcionar como instrumento de mudança das organizações públicas, de melhoria do atendimento ao cidadão e de racionalização do uso de recursos públicos; desempenhar e promover o processo de disseminação da tecnologia de informação e comunicação para que este contribua para o desenvolvimento do país; promoção, uso e disseminação de práticas de Gestão do Conhecimento na administração pública. Outro ponto importante a ser lembrado é o deslocamento dos interlocutores (ELETRÔNICO, 2004, p. 6-7)

\subsection{Políticas de informação}

A informação é um recurso de relevante importância para decisões na esfera pública e privada. Reichard (1998) destaca o comportamento do detentor da informação nem sempre é dirigido para a produção de certeza e transparência. Pois, a retenção de informações atribui certa autonomia, poder e prestígio. De fato, a legislação brasileira, regulando o processo de transparência, tem induzido o gestor público a praticar determinado comportamento informacional. A falta de espontaneidade, motivada pelo apelo da sociedade, gera regras impositivas exigindo do gestor atenção para o interesse público.

Como isso tudo é muito jovial no Brasil, há um longo percurso para se aprender a compreender informações relevantes, confiáveis, tempestivas e compreensíveis (PLATT NETO et al., 2007).

Para muitos gestores públicos é, ainda, um grande desafio programar uma política de informação e conseguir efetivar sua participação na sociedade da informação, já que em diversas situações as políticas de informação são desenvolvidas em caráter imediato para a divulgação de decisões sobre programas e ações direcionadas (FERREIRA; SANTOS; MACHADO, 2012).

A política de informação não pode ser limitada à divulgação de trabalhos ou decisões governamentais, de serviços ou sistemas prestados. Ela precisa ser estabelecida como um conjunto de valores políticos para regular toda a elaboração e a execução das propostas levantadas, assim como todos os fluxos de informações delineados em prol do debate entre a sociedade civil e o Estado.

“[...] a noção de política de informação está muito ligada à definição e posicionamento político no tratamento de qualquer questão que envolva processos e fluxos de informação na sociedade." (MAGNANI; PINHEIRO, 2011, p. 596).

Todas as informações que partem do ente governamental possuem um caráter decisório na quebra da barreira a favor da democracia, possuindo um aprimoramento das ações do gestor público, inibindo atos de corrupção dentro da administração pública e possibilitando uma interação transparente entre o governo e o cidadão.

Ferreira et al. (2012) discutem a política de informação versus a Lei de Acesso à Informação. Neste sentido, discutem que para os cidadãos a principal dificuldade ainda é julgar as ações do gestor público e participar com instruções para cobrar as necessidades da comunidade, por falta de conhecimento e informações necessárias. A política de informação e a Lei de Acesso à Informação, quando trabalhadas com efetividade, poderão trazer oportunidades ao cidadão, como a participação nos processos e na tomada de decisões, vistoriar as ações e omissões do ente governamental seja qual for o nível - todas estas atitudes auxiliam para o monitoramento e combate aos atos de corrupção.

A política de informação possui um marco inicial e histórico evolutivo com a necessidade de haver avanço científico e tecnológico por parte do Estado, e a sociedade percorre um caminho de utilização dos recursos informacionais cada vez maior e constante. A política de informação é vista como uma ferramenta de integração participativa da sociedade com os avanços científicos e tecnológicos, na promoção das condições de educação, cultura e política. E toda esta estrutura possui como elemento prioritário a efetivação do exercício de cidadania (DUTRA; CORREA; RUAS, 2013). A política de informação deve ser presente como um mecanismo de governança na gestão pública para dar efetividade aos atos dos governantes perante a sociedade. 


\section{PROCEDIMENTOS METODOLÓGICOS}

Visando empreender forma integradora dos campos teóricos e empíricos, o presente estudo tem por objetivo unir campos teóricos da Governança Pública e Ciência da Informação, para contribuir com a disseminação de pesquisas interdisciplinares mais bem associadas ao desenvolvimento socioeconômico. Como forma central da pesquisa, as práticas na gestão pública municipal, por dados empíricos, constituem a substância desta investigação.

Isto porque o conhecimento explícito do gestor público tem importância capital na formação dos indivíduos, organizações e sociedade. Justamente é o que este novo campo procura explorar, mobilizando capacidades governamentais e tecnológicas, realizando ações positivas convergentes com os interesses dos cidadãos.

Quanto à abordagem, o presente trabalho, embora utilize alguns aspectos numéricos ilustrativos, se caracteriza com qualitativo. De acordo com Sampieri, Collado e Lucio (2013), estudos qualitativos se caracterizam por serem aplicados em um menor número de casos; em fenômenos ainda não muito bem compreendidos, são orientados para avaliar a realidade mediante certos processos. Nesta pesquisa houve variedade significativa de coleta e exame de materiais empíricos, permitindo a descoberta de práticas dos gestores, o que se reveste de nuances interpretativas típicas de estudos qualitativos (DENZIN; LINCOLN, 2006).

A pesquisa qualitativa é muito conhecida pela integridade de seu pensamento, nesta não existe uma única configuração do pensamento, mas uma coletânea de informações, como interpretativo, situacional e humanístico, os indivíduos serão elencados como únicos, mesmo que semelhantes com outros indivíduos (STAKE, 2011).

Em relação ao objetivo da pesquisa, caracteriza-se como um estudo descritivo (CRESWELL, 2010; SAMPIERI; COLLADO; LUCIO, 2013), pois, mediante fontes informacionais dos municípios, analisa e descreve dados relacionados a práticas de gestão pública de acordo com o conjunto de comandos de transparência pública.
Com a pesquisa descritiva se busca elencar as características dos fenômenos estudados com os detalhes mais apurados, mediante a coleta de dados ou observações sistemáticas, esta pesquisa demanda do pesquisador um estudo mais aprofundado das variáveis relacionadas com o objeto a ser estudado, ela descreve e interpreta os fatos encontrados (SAMPIERI; COLLADO; LUCIO, 2013).

Como técnica, o estudo fez uso da análise de conteúdo (MORAES, 2004), mediante a localização dos dados por sítios eletrônicos, o download desses conteúdos, o exame, mediante a leitura, organização e classificação das informações. Isso contribuiu para análise e o cotejamento com a legislação para elaborar as categorias analíticas do estudo.

A população pesquisada abrangeu a microrregião de Criciúma, composta por 11 municípios, que compõem a mesorregião do Sul Catarinense, conforme mostra a tabela 1 , que contém os municípios, seu número de habitantes e página principal da web. A seleção desta microrregião se deu por se tratar de uma divisão geográfica de proximidades. Destes municípios, apenas o município de Treviso não foi analisado por possuir população abaixo de 10.000 habitantes, não possuindo obrigatoriedade conforme o $\$ 4^{\circ}$ do art. $8^{\circ}$ da Lei ${ }^{\circ} 12.527$, de 18 de novembro de 2011.

As categorias de análise foram consideradas seguindo os ditames da Lei 12.527/2011, compreendendo informações obrigatórias e recomendáveis. A Tabela 01 contém as categorias com as legendas adotadas.

A primeira visita no sítio do município foi para identificar, na página inicial, a existência de alguma informação sobre Transparência, Portal da Transparência e Acesso a Informação, para posteriormente se fazer a análise referente à estrutura do sítio eletrônico, conforme disponibiliza o Guia de implantação do Portal da Transparência baseado na Lei Complementar no 131, de 27 de maio de 2009, em consonância com a com a Lei de Acesso à Informação $12.527 / 2011$. Esta análise compreendeu o período de 26/01 a 10/03/2016.

No período citado foram acessados os 10 municípios analisados - no primeiro momento na página oficial do município (https://www.municipio.sc.gov. br), observada toda a sua estrutura informacional e, posteriormente, visitando as páginas que remetiam 
os ícones dentro do sítio, conforme relatados nos apêndices. Em todos os municípios analisados existem mais de uma página com o nome "Transparência", "Portal da Transparência" ou "Portal de Acesso à Informação", conforme as tabelas que constam da discussão dos resultados.

Quadro 01 Categorias composta por requisitos tecnológicos em sítios eletrônicos

\begin{tabular}{l|l}
\hline \multicolumn{1}{c|}{ Legend. } & \multicolumn{1}{|c}{ Sobre o sítio eletrônico } \\
\hline N_Dom & Nome do domínio \\
\hline R_CP & Registro no www.contaspublicas.gov.br \\
\hline F_Busca & Ferramenta de busca \\
\hline Fale_C & Seção "Fale Conosco" \\
\hline S_P_F & Seção "Perguntas mais frequentes" \\
\hline A_Livre & Acesso livre \\
\hline A_Outros & Acesso por outros sistemas \\
\hline Acessib & Acessibilidade \\
\hline C_Inf & Características da informação \\
\hline G_Rel & Gravação de relatório \\
\hline F_U_E_I & $\begin{array}{l}\text { Formatos utilizados para a estruturação das informa- } \\
\text { çes }\end{array}$ \\
\hline N_Link & $\begin{array}{l}\text { Nome do link estático para acesso ao portal da trans- } \\
\text { parência do município }\end{array}$ \\
\hline A_PT_GF & $\begin{array}{l}\text { Adesão ao Portal da Transparência do Governo } \\
\text { Federal * }\end{array}$ \\
\hline A_B_Prat & Adoção de boas práticas de usabilidade * \\
\hline E_MAG & Suporte ao e-MAG \\
\hline E_PING & Utilização do e-PING \\
\hline Fonte: Dados
\end{tabular}

Fonte: Dados da pesquisa.

Observação: As legendas constantes da primeira coluna dessa Tabela foram base para a identificação de práticas de governança. (*) Práticas recomendáveis.

No período citado foram acessados os 10 municípios analisados - no primeiro momento na página oficial do município (https://www.municipio.sc.gov. br), observada toda a sua estrutura informacional e, posteriormente, visitando as páginas que remetiam os ícones dentro do sítio, conforme relatados nos apêndices. Em todos os municípios analisados existem mais de uma página com o nome "Transparência", "Portal da Transparência" ou "Portal de Acesso à Informação", conforme as tabelas que constam da discussão dos resultados.

Foram identificados que muitos municípios trabalham com o sítio eletrônico da Empresa Betha Sistemas, instituição privada situada no município de Criciúma (http://e-gov.betha.com.br/município), e também com o sítio eletrônico da Federação Catarinense dos Municípios - FECAM (lai.fecam.org. br/município). Apenas o município de Criciúma trabalha com o sitio eletrônico da Empresa Virtualiza, instituição privada situada também no próprio município.

\section{ANÁLISE E DISCUSSÃO DOS RESULTADOS}

$\mathrm{Na}$ análise realizada aos sítios dos municípios da microrregião de Criciúma, ficou identificado que os municípios trabalham com mais de um sítio para transparecer suas atividades, muito com até três, mas a evidência alcançada com os resultados é que no final não alcançam os objetivos propostos, não cumprindo assim as leis estabelecidas para uma boa governança pública.

Com base nas categorias do quadro 01 se analisou todos os municípios que possuem o sítio eletrônico com o tema "Transparência" e a página https:// www.municipio.sc.gov.br; considerou-se a inclusão do município de Criciúma que trabalha com a mesma página, mas utiliza como tema "Acesso a Informação".

No quadro 02 se realizou análise com o tema "Portal da Transparência" e a página https://www.e-gov.betha.com.br. Na tabela 02 não consta o município de Urussanga, por não utilizar esta forma de acesso durante a pesquisa. Considerada a inclusão do município de Criciúma que trabalha com a página, mas utilizando o tema "Contas Abertas".

Os municípios de Balneário Rincão, Içara, Lauro Müller, Siderópolis e Urussanga e utilizam também o sítio eletrônico com o tema "Portal de Acesso à Informação" com a página https://www.lai.municipio. sc.gov.br. Dentre os 10 municípios analisados, cinco trabalham com três sítios eletrônicos cumprindo com a transparência (Balneário Rincão, Içara, Lauro Muller, Siderópolis, Urussanga); outros cinco municípios 
trabalham com dois sítios (Cocal do Sul, Criciúma, Forquilhinha, Morro da Fumaça, Nova Veneza).

O Guia de implantação do Portal da Transparência possui requisitos obrigatórios e recomendáveis, para o atendimento da Lei Complementar $n^{\circ} 131 / 2009$. Na tabela 01, somente o "Nome do domínio, Acesso livre e Características da informação" atenderam ao solicitado em todos os municípios analisados nesta pesquisa. Os itens "Seção perguntas mais frequentes e Acessibilidade" não atendem ao solicitado. A "Adoção de boas práticas de usabilidade" atende parcialmente o solicitado.

Conforma consta no quadro 02 , referente ao assunto "Ferramenta de busca", $10 \%$ dos municípios atenderam ao solicitado, $40 \%$ atenderam parcialmente e $50 \%$ não atenderam. Na seção "Fale Co- nosco", $80 \%$ dos municípios atendem ao solicitado e $20 \%$ atendem parcialmente. Em "Acesso por outros sistemas", apenas $20 \%$ atendem ao solicitado e $80 \%$ não atendem ao solicitado. No assunto "Gravação de relatório", 30\% dos municípios atende e $70 \%$ não atendem. Em "Formatos utilizados para a estruturação das informações”, somente $10 \%$ não atendem ao solicitado, enquanto $80 \%$ atende e $10 \%$ atendem parcialmente. No assunto "Nome do link estático para acesso ao portal da transparência do município", $80 \%$ atendem e $20 \%$ não atendem ao solicitado. Em "Suporte ao e-MAG", nenhum dos municípios atende ao solicitado na íntegra, $80 \%$ atendem parcialmente e $20 \%$ não atendem. No assunto "Utilização do e-PING", $80 \%$ não atendem e $20 \%$ atendem parcialmente ao solicitado.

Quadro 02 Municípios que utilizam o sítio com o nome Transparência

\begin{tabular}{l|c|c|c|c|c|c|c|c|c|c|c|c|c|c}
\hline \multicolumn{1}{c|}{ Casos } & N_Dom & F_Busca & Fale_C & S_P_F & A_Livre & A_Outros & Acessib & C_Inf & G_Rel & F_U_E_I & N_Link & $\begin{array}{c}\text { A_B_- } \\
\text { Prat }\end{array}$ & e_MAG & e_PING \\
\hline Balneário Rincão & AS & APS & AS & NAS & AS & NAS & NAS & AS & NAS & AS & AS & APS & APS & NAS \\
\hline Cocal do Sul & AS & NAS & APS & NAS & AS & NAS & NAS & AS & NAS & AS & AS & APS & APS & NAS \\
\hline Criciúma & AS & AS & APS & NAS & AS & AS & NAS & AS & AS & APS & NAS & APS & NAS & NAS \\
\hline Forquilinha & AS & APS & AS & NAS & AS & AS & NAS & AS & AS & AS & AS & APS & APS & APS \\
\hline Içara & AS & NAS & AS & NAS & AS & NAS & NAS & AS & NAS & AS & AS & APS & APS & NAS \\
\hline Lauro Muller & AS & APS & AS & NAS & AS & NAS & NAS & AS & NAS & AS & AS & APS & APS & NAS \\
\hline Morro da Fumaça & AS & NAS & AS & NAS & AS & NAS & NAS & AS & NAS & AS & AS & APS & APS & NAS \\
\hline Nova Veneza & AS & NAS & AS & NAS & AS & NAS & NAS & AS & AS & NAS & NAS & APS & NAS & NAS \\
\hline Siderópolis & AS & APS & AS & NAS & AS & NAS & NAS & AS & NAS & AS & AS & APS & APS & NAS \\
\hline Urussanga & AS & NAS & AS & NAS & AS & NAS & NAS & AS & NAS & AS & AS & APS & APS & APS \\
\hline
\end{tabular}

Fonte: Dados da pesquisa.

Legenda: Constam na primeira linha dessa Tabela as categorias analisadas (ver quadro 01). AS - Atende ao solicitado, APS - Atende parcialmente ao solicitado, NAS - Não atende ao solicitado. E-MAG - Modelo de acessibilidade em governo eletrônico, E-PING - Padrões de interoperabilidade de governo eletrônico.

Conforma consta do quadro 02 , referente ao assunto "Ferramenta de busca", $10 \%$ dos municípios atenderam ao solicitado, $40 \%$ atenderam parcialmente e $50 \%$ não atenderam. Na seção "Fale Conosco", $80 \%$ dos municípios atendem ao solicitado e $20 \%$ atendem parcialmente. Em "Acesso por outros sistemas", apenas $20 \%$ atendem ao solicitado e $80 \%$ não atendem ao solicitado. No assunto "Gravação de relatório", 30\% dos municípios atende e $70 \%$ não atendem. Em "Formatos utilizados para a estruturação das informações", somente $10 \%$ não atendem ao solicitado, enquanto $80 \%$ atende e $10 \%$ atendem parcialmente. No assunto "Nome do link estático para acesso ao portal da transparência do município", $80 \%$ atendem e $20 \%$ não atendem ao solicitado. Em
“Suporte ao e-MAG”, nenhum dos municípios atende ao solicitado na íntegra, $80 \%$ atendem parcialmente e $20 \%$ não atendem. No assunto "Utilização do e-PING", $80 \%$ não atendem e $20 \%$ atendem parcialmente ao solicitado.

No quadro 03, quanto ao "Acesso livre", "Acesso por outros Sistemas", "Características da informação" e "Gravação de relatórios", todos os municípios analisados atendem ao solicitado. Vê-se que o "Nome do domínio", "Ferramenta de busca", "Seção Fale Conosco", "Seção Perguntas mais frequentes", "Acessibilidade", "Nome do link estático para acesso ao portal da transparência do município" e "Utilização do e-PING", nenhum dos municípios atende ao solicitado. O assunto "Adoção de boas práticas de usabi- 
lidade" e "Suporte ao e-MAG" atende parcialmente o solicitado. Com o assunto "Formatos utilizados para a estruturação das informações", $81 \%$ dos municípios atendem e $9 \%$ atendem parcialmente.

Quadro 03 Municípios que utilizam o sítio com o nome Portal da Transparência

\begin{tabular}{l|c|c|c|c|c|c|c|c|c|c|c|c|c|c}
\hline \multicolumn{1}{c|}{ Casos } & N_Dom & F_Busca & Fale_C & S_P_F & A_Livre & A_Outros & Acessib & C_Inf & G_Rel & F_U_E_I & N_Link & $\begin{array}{c}\text { A_B_- } \\
\text { Prat }\end{array}$ & e_MAG & e_PING \\
\hline Balneário Rincão & NAS & NAS & NAS & NAS & AS & AS & NAS & AS & AS & AS & NAS & APS & APS & NAS \\
\hline Cocal do Sul & NAS & NAS & NAS & NAS & AS & AS & NAS & AS & AS & AS & NAS & APS & APS & NAS \\
\hline Criciúma & NAS & NAS & NAS & NAS & AS & AS & NAS & AS & AS & AS & NAS & APS & APS & NAS \\
\hline Forquilinha & NAS & NAS & NAS & NAS & AS & AS & NAS & AS & AS & AS & NAS & APS & APS & NAS \\
\hline Içara & NAS & NAS & NAS & NAS & AS & AS & NAS & AS & AS & AS & NAS & APS & APS & NAS \\
\hline Lauro Muller & NAS & NAS & NAS & NAS & AS & AS & NAS & AS & AS & AS & NAS & APS & APS & NAS \\
\hline Morro da Fumaça & NAS & NAS & NAS & NAS & AS & AS & NAS & AS & AS & AS & NAS & APS & APS & NAS \\
\hline Nova Veneza & NAS & NAS & NAS & NAS & AS & AS & NAS & AS & AS & AS & NAS & APS & APS & NAS \\
\hline Siderópolis & NAS & NAS & NAS & NAS & AS & AS & NAS & AS & AS & AS & NAS & APS & APS & NAS \\
\hline Urussanga & NAS & NAS & NAS & NAS & AS & AS & NAS & AS & AS & AS & NAS & APS & APS & NAS \\
\hline
\end{tabular}

Fonte: Dados da pesquisa.

Legenda: Constam na primeira linha dessa Tabela as categorias analisadas (ver quadro 01). AS - Atende ao solicitado, APS - Atende parcialmente ao solicitado, NAS - Não atende ao solicitado. E-MAG - Modelo de acessibilidade em governo eletrônico, E-PING - Padrões de interoperabilidade de governo eletrônico.

Todos os municípios que possuem o sítio eletrônico com o nome "Portal da Transparência" (https:// www.e-gov.betha.com.br) atendem ao solicitado, $31,25 \%$ todos requisitos para atendimento à LC $131 / 2009,12,50 \%$ atendem parcialmente e $56,25 \%$ não atendem ao solicitado, conforme estabelece o "Guia Implantação de Portal da Transparência", referente aos requisitos obrigatórios e recomendáveis.

Os autores Guimarães (2008) e Peci et al. (2008) corroboram que a governança pública exerce um papel importante para amenizar os conflitos existentes, criar diálogos, métodos de monitoramento, controle e divulgação das informações, entre o gestor público e a sociedade civil. Estas atividades serão efetivas por intermédio do cumprimento dos mecanismos de governança.

A Lei no 12.527 de 18 de novembro de 2011, no seu artigo $8^{\circ}$, define que é "dever dos órgãos e entidades públicas promover, independentemente de requerimentos, a divulgação em local de fácil acesso", em consonância com a Lei Complementar n ${ }^{\circ} 131$ de 27 de maio de 2009, que "determina a disponibilização em tempo real”. Com a análise realizada, verificou-se que estas leis não são cumpridas.

Os portais da transparência analisados não atingem os objetivos estatuídos pelas normas informacionais, pois são inefetivos e falhos em suas propostas. Conforme afirmam os autores Paula, Cianconi (2007) e Loureiro, Teixeira e Prado (2008), o Portal da Trans- parência dos municípios deve ter duas características prioritárias, o compartilhamento de informações e a prestação de serviços on-line, para uma gestão integrada com a sociedade e o gestor público. Com a construção da sua estrutura de forma clara e objetiva, sem a utilização de senhas ou impedimentos, pois deverá ser de fácil e compreensivo acesso a todos os níveis da sociedade. Os achados convergem com Platt Neto et al. (2007), quando destacaram que divulgações das contas públicas no campo da transparência governamental apresentam limitações, merecendo aperfeiçoamento de tal modo a favorecer o exercício do controle social.

Para de Freire (2008), o acesso à informação não deve ser realizado por mero cumprimento de leis ou inclusão da sociedade na era da informação, mas com o propósito de oportunizar o crescimento intelectual por intermédio da informação repassada, colocando o cidadão como agente principal na construção da sociedade.

\section{CONSIDERAÇÕES FINAIS}

Este estudo procurou compreender as formas de divulgação nos sítios eletrônicos dos municípios da microrregião de Criciúma com população acima de 10.000 habitantes, seguindo como base o Guia de Implantação do Portal de Transparência. Conforme 
o art. $8^{\circ}, \S 4$ da lei $12.527 / 2011$, foram analisados os municípios de Balneário Rincão, Cocal do Sul, Criciúma, Forquilhinha, Içara, Lauro Müller, Morro da Fumaça, Nova Veneza, Siderópolis e Urussanga, que compõem a microrregião de Criciúma.

O guia possui o objetivo de orientar os gestores públicos no cumprimento da Lei complementar $\mathrm{n}^{\circ} 131 / 2009$, que determina a disponibilização em tempo real de informações pormenorizadas sobre a execução orçamentária e financeira, em parceria com a Lei $\mathrm{n}^{\circ} 12.527 / 2011$, que regula o acesso à informação.

De acordo com o propósito da investigação, o estudo foi conduzido com base nos dados dispostos nas estruturas de sítios eletrônicos. Considerando as categorias de análise (ver Tabela 01), evidencia-se incidência predominante de descumprimento informacional. Este achado viola o princípio de transparência fixado na legislação, revelando a presença de barreira informacionais à sociedade.

Neste campo, as normas que dimanam do poder legislativo conferem à gestão pública o exercício da transparência. Predominam o espírito de permissão a participação popular, consultas aos dados públicos, processos divulgacionais da gestão, vigilância e controle social. Por esse conjunto de pressupostos da boa governança se pode avaliar a conduta do governante público. No entanto, considerando o objeto de análise, os dados demonstram práticas incompletas e, portanto, desídia dos gestores públicos. Assim, no âmbito do contexto sob exame, não se pode afirmar que os gestores cumprem ou exercem boas práticas de governança e, com isso, carecem em relação à produção de informações pertinentes as recomendações legais à sociedade.

Logo, a questão de pesquisa possui sua resposta negativa, pelo fato dos gestores públicos não estarem cumprindo os mecanismos de governança propostos para uma gestão pública pautada em responsabilização, participação e transparência. Tais violações sugerem imaturidade na gestão pública da região sob análise, pois não há atenção dirigida para o rol de orientações estabelecidas pelo legislador, por sua vez, frustrando as expectativas sociais.

A análise foi baseada na tabela que compõe os requisitos obrigatórios e desejáveis sobre a estrutura do sítio eletrônico. Nos dez municípios analisados,
$50 \%$ possuem três sítios eletrônicos com nomes diferentes, em que uma página possui ícones que remetem para a outra; os outros $50 \%$ dos municípios possuem dois sítios.

A literatura que ampara o presente estudo revela nova consideração ao gerenciamento da coisa pública. Avanços na gestão pública foram induzidos por melhores práticas consagradas no ambiente privado. Por exemplo, o conceito de governança no âmbito das organizações contribuiu para a implementação de políticas públicas e mecanismos de controle do gestor. A essência da governança pública, numa visão moderna, está relacionada à base institucional e de redes informacionais. Com isso, de uma visão essencialmente unitária e regulatória progride para aspectos plurais, ampliando os canais de interessados em questões públicas. A ideia de redes relacionais induz a governança mais aberta, sujeita, portanto, a observações, discussões, participações e convergência de interesses.

O exame dos dados não permite afirmar que os municípios dessa região adotam e empreendem boas práticas de governança pública. Isso porque, evidenciou-se não cumprimento das exigências e recomendações normativas. Por tais práticas - ou descumprimentos, desafiam à sociedade. A ausência de penalização e fiscalização mais prudente dos agentes incentiva a desatenção. A falta de penalização compatível com a desobediência produz incertezas e torna a legislação inócua.

A constituição de organizações não governamentais - como observatórios, por exemplo, pode ser explicada pela inefetividade das normas e da conduta do gestor público. Justamente, por que entidades públicas carecem de práticas interativas de seus atos, gerando barreiras informacionais, contribuindo para o aumento do custo social e desestimular o exercício da cidadania.

Em síntese, a sociedade não recebe a devida prestação de contas com transparência, inibindo demandas sociais adequadas. Demonstra que o gestor, uma vez imbuído em seu poder de agente público, mesmo escolhido pela população, não atende a imposições normativas, ferindo regras e cerceando anseios mínimos da população. Isso demonstra não atendimento às normas e ao legislador, desafiando, inclusive, as instituições fiscalizadoras dos atos 
do gestor, gerando, por sua vez, um custo social importante. Esses descumprimentos demonstram conflitos de interesses entre o gestor, o legislador, as instituições fiscalizadoras e a sociedade em geral, vulnerabilizando normas fixadoras de comportamentos informacionais, justamente por serem inócuas e inefetivas. Impendem avanços sociais na medida em que os agentes públicos deixam de oferecer dados e informações suficientes para o cotejo histórico de sua governança, limitando assim indagações e pleitos da sociedade.

De fato, em síntese, os dados empíricos analisados, com base nos municípios da microrregião de Criciúma, sugerem que o gestor público não está exercendo seu papel de governante pautado nos princípios de governança, transparência, equidade, cumprimento das leis, prestação de contas e a conduta ética.

Ante tais descobertas, emergem as seguintes indagações: i) o gestor público não cumpre normas informacionais por que não há penalidades relevantes ou impedimentos em relação à sua conduta?; ii) é do interesse do gestor público tornar públicas somente informações que lhe proporcionam vantagens ou benefícios?; iii) quanto mais conteúdo informacional, mais intensivas serão as demandas sociais, e isso pode gerar certa pressão ao gestor. logo, a ampliação de conteúdo informacional pode ser um indutor de demandas sociais?; e iv) comportamentos reprováveis do gestor produzem custos sociais constituídos por meio de organizações não governamentais de controle. logo, a presença mais intensiva de organizações não governamentais, de controle da gestão pública, pode ser explicada são deeorrentes do pelo comportamento oportunista do agente público?

Como limitação, a presente pesquisa examinou apenas alguns municípios da região Sul Catarinense, e dessa forma não pode proporcionar generalizações quanto a práticas de governança pública no que diz respeito a aspectos informacionais. Os dados da pesquisa foram extraídos em momento distintos e não refletem o panorama atual. Devido à dinâmica, pode ser que os gestores tenham ampliado o escopo informacional à sociedade. Esse estudo não circularizou no sentido de colher impressões e conhecimento da sociedade sobre informações obrigatórias do gestor público e demandas sociais. Poderia, pois, ter en- trevistado os gestores quanto ao conhecimento das normas e investigado os motivos da inefetividade da gestão quanto a práticas de governança pública.

Para estudos futuros sugere-se ampliar a análise aos demais municípios da região Sul Catarinense e até os municípios de todo o Estado de Santa Catarina. Sugere-se entrevistar o legislador, o controlador dos atos de gestão e compreender porque não há efetividade em relação ao arcabouço da legislação pertinente, ou seja: a que estabelece normas de Finanças Públicas voltadas para a responsabilidade na gestão fiscal (Lei Complementar no 101/2000); a que determina a disponibilização, em tempo real, de informações pormenorizadas sobre a execução orçamentária e financeira da União, dos Estados, do Distrito Federal e dos Municípios (Lei Complementar no 131/2009); a que dispõe sobre o padrão mínimo de qualidade do sistema integrado de administração financeira e controle (Decreto $n^{\circ} 7.185 / 2010$; ou a que regula o acesso à informação (Lei no ${ }^{\circ}$ 2.527/2011).

Como implicações práticas, necessário realizar uma análise ao conteúdo exigido no Guia de Implantação do Portal da Transparência nos mesmos municípios da microrregião de Criciúma, para poder cruzar as análises encontradas e identificar até onde uma estrutura prejudica o conteúdo proposto. Realizar posteriormente uma pesquisa com os gestores públicos e com os cidadãos em determinados municípios, poderiam ser capitais, para verificar o conhecimento e a percepção dos atuantes na gestão pública e dos cidadãos em relação à importância do ato de transparecer.

Sugere-se aproximação com gestores públicos para identificar o grau de responsabilização com a gestão pública, se possui o conhecimento sobre os portais de transparência e sua importância, se não tem domínio sobre o assunto se possui o interesse de ir buscar este conhecimento e estar conscientizando todos os colaboradores sobre a importância do assunto, realizando a transferência deste conhecimento por intermédio informações para o cidadão, para a realização de uma gestão pública efetiva e eficaz. Igualmente, com o cidadão com o intuito de identificar o conhecimento dos mesmos sobre o assunto, se em seu município o gestor público possui o habito de informar ou se é necessário à cobrança para haver a transparência. 


\section{REFERÊNCIAS}

AUN, M.; CÂMARA, M. A. From lacking until sustainability: informatics inclusion as an option for freedom. 10 p., Mar. 2005. Disponível em: <www.globaledevelopment.org/papers/FromLackingUntilSustainability. pdf>. Acesso em: 18 maio 2005.

BRASIL. Lei Complementar $n^{\circ} 101$, de 4 de maio de 2000. Estabelece normas de finanças públicas voltadas para a responsabilidade na gestão fiscal e dá outras providências. Diário Oficial da União, 2000. Disponível em: <http://www.planalto.gov.br/ ccivil_03/leis/LCP/Lcp101.htm>. Acesso em: 13 de maio 2014.

. Lei Complementar $n^{\circ} 131$, de 27 de maio de 2009. Estabelece normas de finanças públicas voltadas para a responsabilidade na gestão fiscal e dá outras providências, a fim de determinar a disponibilização, em tempo real, de informações pormenorizadas sobre a execução orçamentária e financeira da União, dos estados, do Distrito Federal e dos Municípios. Disponível em: <http://www.planalto. gov.br/CCIVIL_03/leis/LCP/Lcp131.htm >. Acesso em: 13 de maio 2014.

. Decreto no 7.185, de 27 de maio de 2010. Dispõe sobre o padrão mínimo de qualidade do sistema integrado de administração financeira e controle no âmbito de cada ente da Federação, nos termos do art. 48 , parágrafo único, inciso III, da lei Complementar no 101, de 4 de maio de 2000, e dá outras providências. Disponível em: $<$ http://www.planalto.gov.br/ccivil_03/_ato2007-2010/2010/decreto/ d7185.htm>. Acesso em: 13 de maio 2014.

Lei Federal n. 12.527, de 18 de novembro de 2011. Regula o acesso a informação previsto no inciso XXXIII do art. $5^{\circ}$ no inciso II do $\$ 3^{\circ}$ do art. 37 e no $\$ 2^{\circ}$ do art. 216 da Constituição Federal; altera a Lei $\mathrm{n}^{\circ}$ 8.112, de 11 de dezembro de 1990; revoga a Lei $\mathrm{n}^{\circ} 11.111$, de 5 de maio de 2005, e dispositivos da Lei nº.159 de 8 de janeiro de 1991; e dá outras providências. Disponível em: $<$ http://www.planalto. gov.br/ccivil_03/_ato2011-2014/2011/lei/112527. htm >. Acesso em: 13 de maio 2014.
CONDE, R. D. V. Governança pública: uma análise comparativa do sistema de indicadores das fundações estaduais de amparo à pesquisa. 2015. 138 f. Dissertação (Mestrado Profissional em Gestão Pública Para o Desenvolvimento do Nordeste)Universidade Federal de Pernambuco, Recife, 2015.

CRESWELL, John W. Projeto de pesquisa: métodos qualitativo, quantitativo e misto. Tradução Magda Lopes. - 3. Ed. - Porto Alegre: Artmed, 296 p. 2010.

CUNHA, M. A. V. C. D.; SANTOS, G. S. D. O uso de meios eletrônicos no relacionamento do parlamentar com o cidadão nos municípios brasileiros. Organizações \& Sociedade, v. 12, n. 35, p. 69-89, Out./Dez. 2005.

FREIRE, G. H. de A. Construção participativa de Instrumento de política pública para gestão e acesso à informação. Perspectivas em Ciência da Informação, v. 13, n. 3, p. 195-207, Set./Dez. 2008.

DE CASTRO ALCÂNTARA, V; PEREIRA, J. R.; FERREIRA SILVA, É. A. Gestão Social e Governança Pública: aproximações e (de) limitações teórico-conceituais. Revista de Ciências da Administração, v. 17, Dez. 2015.

DENZIN, N.; LINCOLN, Y. Introdução: a disciplina e a prática da pesquisa qualitativa. O Planejamento da pesquisa qualitativa: teorias e abordagens. 2. ed. Porto Alegre: Artmed, 2006.

DUTRA, D. M. R.; CORRÊA, R. A.; RUAS, W. J. Política de informação nas organizações. Pós em Revista, v. 16, n. 7, 2013.

ELETRÔNICO, C. E. D. G. Oficinas de Planejamento Estratégico: relatório consolidado. Ministério do Planejamento. 2004.

FECAM. Federação Catarinense dos Municípios. Guia dos Municípios Catarinenses 2015/2016, $7^{\text {a }}$ edição, 2015. 
FERREIRA, E. G. A.; SANTOS, E. S.; MACHADO, M. N. Políticas de informação no Brasil: A Lei de Acesso à Informação em foco. Múltiplos Olhares em Ciência da Informação, v. 2, n. 1, p. 1-13, Mar. 2012.

FIGUEIREDO, L. V. Instrumentos da administração consensual. A audiência pública e sua finalidade. Revista de Direito Administrativo, v. 230, p. 237250, Out./Dez. 2002.

GOVERNO DIGITAL. Ministério do Planejamento, Desenvolvimento e Gestão. Governo eletrônico. Disponível em: < https://www.governodigital.gov.br/ EGD/historico-1/historico>. Acesso em: 06 ago. 2015.

KISSLER, L.; HEIDEMANN, F. G. Governança pública: novo modelo regulatório para as relações entre Estado, mercado e sociedade? Revista de Administração Pública, v. 40, n. 3, p. 479-499, Maio/ Jun. 2006.

LOUREIRO, M. R.; TEIXEIRA, M. A. C.; PRADO, O. Construção de instituições democráticas no Brasil contemporâneo: transparência das contas públicas. Organizações \& Sociedade, v. 15, n. 47, p. 107-119, Out./Dez. 2008.

MAGNANI, M. C. B.; PINHEIRO, M. M. K. "Regime" e "Informação": a aproximação de dois conceitos e suas aplicações na Ciência da Informação. Liinc em Revista, v. 7, n. 2, p. 593-610, Set. 2011.

MELO, E. A. D.; MONTEIRO, A. D. O.; FADUL, É. Controle do gasto público e responsabilidade fiscal: o caso da Administração Municipal de Salvador. Organizações \& Sociedade, v. 14, n. 41, p. 161-175, Abr./Jun. 2007.

MICHENER, G.; MONCAU, L. F.; VELASCO, R. B. Estado brasileiro e transparência: avaliando a aplicação da Lei de Acesso à Informação. Rio de Janeiro: FGV e Open Society Foundations, 2014.

MORAES, M. C. Pensamento eco-sistêmico: educação, aprendizagem e cidadania no século XXI. Petrópolis, Rio de Janeiro: Vozes, 2004.
JUSTINO DE OLIVEIRA, G. H. As audiências públicas e o processo administrativo brasileiro. Revista Direito Administrativo, v. 209, p. 153-167, Jul./Set. 1997.

OSBORNE, S. P. The new public governance? Public Management Review, n. 8, v. 3, p 377-387, Fev. 2007.

OSBORNE, S. P. (Ed.). The new public governance? Emerging perspectives on the theory and practice of public governance. London: Routledge. 2010.

PATAPAS, A. New Public Governance: The Tracks of Changes. International Journal of Business and Social Research, v. 4, n. 5, p. 25-32, Maio 2014.

PAUlA, D. R. ; DE CIANCONI, R. B. Práticas de gestão do conhecimento: caso dos sítios associados ao portal corporativo da FIOCRUZ. Perspectivas em Ciência da Informação, v. 12, n. 2, p. 49-63, Maio/ Ago. 2007.

PLATT NETO, O. A.; DA CRUZ, F.; ENSSLIN, S. R.; ENSSLIN, L. Publicidade e transparência das contas públicas: obrigatoriedade e abrangência desses princípios na administração pública brasileira. Contabilidade Vista \& Revista, v. 18, n. 1, p. 75-94, Jan./Mar. 2007.

RAUSCH, R. B.; SOARES, M. Controle social na administração pública: a importância da transparência das contas públicas para inibir a corrupção. Revista de Educação e Pesquisa em Contabilidade, v. 4, n. 3, p. 23-43, Set./Dez. 2010.

REICHARD, C. The impact of performance management on transparency and accountability in the public sector. In A. HONDEGHEM (ed.). Ethics and accountability in a context of governance and new public management. Ed.: IOS Press, Amsterdam, p. 123-137, 1998.

ROCHA, A. C. A realização da accountability em pareceres prévios do Tribunal de Contas de Santa Catarina. Revista de Administração Pública, v. 47, n. 4, p. 901-926, Jul./Ago. 2013. 
RODRIGUES, J. G. L. Diretrizes para implantação da governança de TI no setor público brasileiro à luz da teoria institucional. Dissertação (mestrado)

- Universidade de Brasília, Brasília, 2010.

SAMPIERI, R. H.; COLLADO, C. H.; LUCIO, P. B.; MURAD, F. C.; GARCIA, A. G. Q. Metodologia de pesquisa. 5. ed. São Paulo: Mc-Graw-Hill, 2013.

SANTOS, C. S. D. Introdução à gestão pública. 1. ed. São Paulo: Saraiva, 2006.
SANTOS, E. M.; DUARTE, E. A.; PRATA, N. V. Cidadania e trabalho na sociedade da informação: uma abordagem baseada na competência informacional. Perspectivas em ciência da informação, v. 13, n. 3, p. 208-222, Set./Dez. 2008.

SILVA, E. R. G. da; OLIVEIRA, T. P. S. de. Economia do Conhecimento: livro didático. Palhoça: UnisulVirtual, 2012.

STAKE, R. E. Pesquisa qualitativa: estudando como as coisas funcionam. Tradução: Karla Reis; revisão técnica: Nilda Jacks. Porto Alegre: Penso, 2011. 